\title{
Correspondence
}

\section{Hyponatraemia and CSF drainage in posthaemorrhagic hydrocephalus}

\section{Sir,}

MacMahon and Cooke ${ }^{1}$ have shown that repeated cerebrospinal fluid drainage in low birthweight babies can create a negative sodium balance due to extra loss of sodium. They do not, however, exclude excessive renal sodium leak or syndrome of inappropriate antidiuretic hormone secretion (SIADHS). SIADHS has been well documented in neonates ${ }^{2} \mathbf{3}$ and intracranial haemorrhage is a known predisposing factor. Sodium content of tapped cerebrospinal fluid can be measured easily and accurate replacement done. As the tapping continues occasional serum sodium estimation could be done to exclude hyponatraemia, which, if present, would be due to causes other than sodium loss. Before giving the massive sodium supplements of the magnitude of $23 \mathrm{mmol} / \mathrm{kg} /$ day that were needed in MacMahon and Cooke's second case, one must exclude SIADHS. Differentiation of these two conditions is crucial, as treatment of each is diametrically opposite. Simultaneous measurements of serum and urinary osmolality would resolve the question in most patients.

\section{B SINGH \\ Department of Paediatrics, King Khalid National Guard Hospital, PO Box 9516, Jeddah, Saudi Arabia}

\section{Drs MacMahon and Cooke comment:}

All the infants we reported were at least 20 days old when sodium supplements were commenced. A particularly large renal sodium leak is atypical in well infants at this postnatal age. Although the syndrome of inappropriate antidiuretic hormone secretion (SIADHS) is associated with intraventricular haemorrhage this usually occurs at the time of the haemorrhage and not later on when obstructive hydrocephalus has developed. We agree, however, that it would be prudent to investigate for renal sodium loss and SIADHS should the electrolyte disturbances we described recur despite sodium replacement equal to the sodium loss in the drainage cerebrospinal fluid (CSF). The purpose of our report was to draw attention to the occurrence of electrolyte disturbances during repeated CSF drainage. Previous reports have specifically stated that this was not a problem. ${ }^{45}$

\section{References}

1 MacMahon P, Cooke RWI. Hyponatraemia caused by repeated cerebrospinal fluid drainage in post haemorrhagic hydrocephalus. Arch Dis Child 1983;58:385-6.
2 Kaplan SL, Feigin RD. Inappropriate secretion of antidiuretic hormone complicating neonatal hypoxicischemic encephalopathy. J Pediatr 1978;92:431-3.

3 Fisher DA, Pyle HR, Jr, Porter JC, Beard AG, Panos TC. Control of water balance in the newborn. Am J Dis Child 1963;106:137-46.

4 Al-Dahhan J, Haycock GB, Chantler C, Stimmler L. Sodium homeostasis in term and preterm neonates. Arch Dis Child 1983;58:335-42.

5 Papile LA, Burstein J, Burstein R, Koffler H, Koops BL, Johnson JD. Post-hemorrhagic hydrocephalus in low birthweight infants: treatment by serial lumbar punctures. J Pediatr 1980;97:273-7.

\section{Perinatal listeriosis and hospital cross infection}

Sir,

Listeria monocytogenes is associated with severe disease in the fetus and the newborn infant and in the past has been associated with high morbidity and mortality. ${ }^{1}$ Even 50 years after its original description, the epidemiology and pathogenesis of perinatal listeriosis is not fully understood. The development of a phage typing system, ${ }^{2}$ with its ability to differentiate between strains of different origin raises hopes of obtaining useful epidemiological information on clusters of cases and in instances of hospital cross infection. We have already reported its use in the study of outbreaks involving adults and neonates ${ }^{34}$ and here report two more cases where phage typing of isolates from neonates supports the view that cross infection occurred.

Both infants were born at term, the mothers came from different geographical areas of Leicester, and there was no history of miscarriage or abortion. They did not note any episodes of diarrhoea during pregnancy but the mother of the first baby suffered an influenza like illness two months before delivery. Both mothers had an uneventful puerperium and listeria was not isolated from high vaginal swabs.

\section{Case 1}

A boy of 38 weeks' gestation, weighing $2400 \mathrm{~g}$, had an early onset disease, and presented with respiratory distress at birth. Liquor was meconium stained. Surface swabs showed heavy growth of $L$. monocytogenes but blood and cerebrospinal fluid were sterile, although the latter had an increased number of leucocytes, mainly polymorphonuclears. He made satisfactory progress after treatment with ampicillin and gentamicin.

\section{Case 2}

A girl born at 39 weeks' gestation, weighing $3260 \mathrm{~g}$, was nursed with the mother until day 8 , when she became ill and septicaemia and meningitis were diagnosed. 